\title{
Differences in chemosensory response between eyed and eyeless Astyanax mexicanus of the Rio Subterráneo cave
}

\author{
Jonathan Bibliowicz ${ }^{1 \dagger}$, Alexandre Alié ${ }^{1 \dagger}$, Luis Espinasa ${ }^{2}$, Masato Yoshizawa $^{3}$, Maryline Blin ${ }^{1}$, Hélène Hinaux ${ }^{1}$, \\ Laurent Legendre ${ }^{1}$, Stéphane Père ${ }^{1}$ and Sylvie Rétaux ${ }^{1 *}$
}

\begin{abstract}
Background: In blind cave-dwelling populations of Astyanax mexicanus, several morphological and behavioral shifts occurred during evolution in caves characterized by total and permanent darkness. Previous studies have shown that sensory systems such as the lateral line (mechanosensory) and taste buds (chemosensory) are modified in cavefish. It has long been hypothesized that another chemosensory modality, the olfactory system, might have evolved as well to provide an additional mechanism for food-searching in troglomorphic Astyanax populations.

Findings: During a March 2013 cave expedition to the Sierra de El Abra region of San Luís Potosi, Mexico, we tested chemosensory capabilities of the Astyanax mexicanus of the Rio Subterráneo cave. This cave hosts a hybrid population presenting a wide range of troglomorphic and epigean mixed phenotypes. During a behavioral test performed in situ in the cave, a striking correlation was observed between the absence of eyes and an increased attraction to food extract. In addition, eyeless troglomorphic fish possessed significantly larger naris size than their eyed, nontroglomorphic counterparts.
\end{abstract}

Conclusions: Our findings suggest that chemosensory capabilities might have evolved in cave-dwelling Astyanax mexicanus and that modulation of naris size might at least partially underlie this likely adaptive change.

Keywords: Behavior, Cavefish, Evolution, Hybrid population, Micos, Olfaction, Sensory system, Vision

\section{Findings}

Introduction

Cave-dwelling animals have long been recognized as excellent models for evolutionary biology [1]. Comparative studies of cave-dwelling (cavefish, CF) and surface-dwelling (surface fish, SF) morphs of the teleost fish Astyanax mexicanus have revealed several adaptations to life in dark cave environments [2-5], which have occurred during a few million years of evolution from a common SF-like ancestor [6]. In CF, temporal and spatial modulations in early developmental signaling pathways appear to influence brain development and organization [7-9]. Lateral line neuromasts on the head are more numerous and mediate a special mechanosensory behavior in response to vibrations on the

\footnotetext{
* Correspondence: retaux@inaf.cnrs-gif.fr

${ }^{\dagger}$ Equal contributors

'Equipe Développement Evolution du Cerveau Antérieur, UPR3294 N\&D,

CNRS, Institut Alfred Fessard, Gif-sur-Yvette F-91198, France

Full list of author information is available at the end of the article
}

water surface [5]. Chemosensory structures are also modified, as CF possess a higher number of taste buds than their SF counterparts $[4,10]$, and studies in a laboratory setting suggest that laboratory-raised CF originating from the Pachón cave might possess higher olfactory capabilities [11]. Thus, sensory modalities of CF might have evolved as an adaptation to life in dark caves for navigation, mate recognition and food-searching. However, the possibility that these changes might provide a sensory compensation for finding food in the dark has yet to be tested directly in natural cave environments.

\section{Results}

The Rio Subterráneo cave is located southwest of the Sierra de El Abra region in the Micos area of Mexico $[12,13]$. We visited this cave, which is inhabited by bats, in March 2013 (the dry season). We could document that the Subterráneo pools contain a wide array of

\section{Biomed Central}




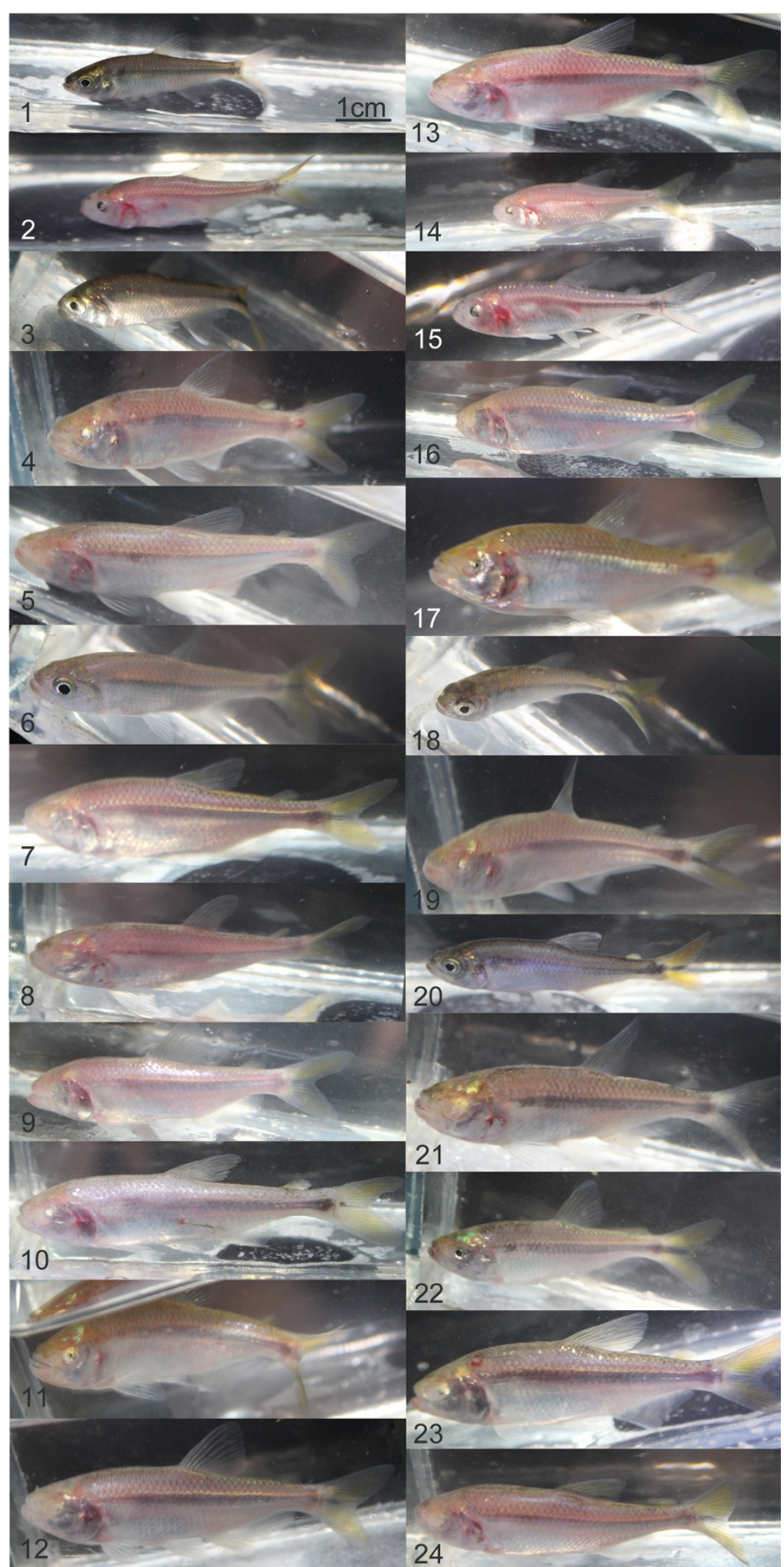

Figure 1 (See legend on next page.) 
intermediate hybrid phenotypes that live alongside more troglomorphic fish (Figure 1). This is probably due to seasonal migration of SF into the Subterráneo cave after flooding and subsequent introgression in the existing cave population $[12,14,15]$. This fact provides a rare possibility to simultaneously test the chemosensory behavior of several morphotypes corresponding to F2 hybrid individuals.

In this unique context, we set out to test the sensorydependent food-finding capabilities of Subterráneo fish. To be able to accurately test and quantify this behavior, we chose to collect a representative group of fish and performed our experiment in an enclosed area. The nine fish collected comprised both eyed and eyeless phenotypes, with eyeless fish being also mostly depigmented. The former were classified as SF-like and the latter as CF-like (Figure 2A). Using a specially designed behavioral testing system recently developed in our laboratory and infrared video recording equipment for filming in the dark, we were able to minimize any disturbances to the fish during the experiment. The fish were subjected to a choice test in which food extract was administered to one corner of an enclosed area and water (control) to the other corner (Figure 2B).

To quantify attraction of fish to the food extract, we analyzed the movie and counted the number of fish that were at the corner of the pool perfused with either the food extract or the water at 10-s intervals during the first minute of the test. Strikingly, the fish that were attracted were all CFlike (Figure 2C). They came to the food source within $20 \mathrm{~s}$ after extract administration, continuously swam toward and around the source, occasionally appearing to bite on the tube end (Additional file 1: movie online). They also displayed behavior very similar to the feeding behavior often seen in the laboratory, which includes increased activity combined with a typical feeding body position [16]. Although at any given time a few of the CF-like fish came at the extract-infused corner, each of them approached the odorant tube at some point during the test. They spent an average of $24 \mathrm{~s}$ in the extract-infused area, which was significantly more than the $1.8 \mathrm{~s}$ spent in the control area during the 1 -min test $(P<0.01)$ (Figure 2D). Conversely, none of the SF-like fish approached the food extract corner throughout the test $(P<0.01$ compared with CF-like fish). Photographs of individual fish taken after the test further revealed significantly larger naris size in CF-like individuals than in
SF-like individuals (Figure 3), reflecting an olfactory-related troglomorphic variation in the Subterráneo population.

Our findings reveal an apparent correlation between troglomorphic characteristics and chemosensory-dependent feeding behavior in wild Astyanax fish of the Subterráneo cave. Previous studies in a laboratory setting suggested that adult Astyanax Pachón cavefish are significantly better than their SF counterparts at finding food in the dark [17]. It has recently been suggested that one of the mechanisms that may contribute to this feeding success in cavefish is their ability to sense vibration using vibration attraction behavior (VAB), a behavior that is mediated through the mechanosensory function of their neuromasts [5]. Since vibrations should be equal on both food extract and control sides of our experimental setup, differences in VAB do not likely contribute to the attraction of CF-like individuals to the food extract that is absent in SF-like fish. Our findings suggest that modified chemosensory capabilities in cavefish do indeed provide a sensory compensation for foodsearching in dark cave environments. The fact that heightened chemosensory capabilities has been observed in both laboratory-raised Pachón and wild Subterráneo fish, which come from two independently derived stocks [14], also suggests a possible convergence of this capacity.

Furthermore, the fact that all food extract-responsive fish possessed enlarged nares and strongly reduced eyes shows a correlation between eye loss and modifications in olfactory-related morphology in this population. Although several mechanisms might underlie the observed heightened chemosensory capabilities in CF-like fish, modulations of naris size could be one contributing factor. Incidentally, our results also show that Astyanax can respond to a food extract to which they have never been exposed before (in this case, commercial granular fish food). The fact that only the CF-like individuals responded to this novel food might reflect a more generalist food detection ability of troglomorphic fish. If confirmed, such opportunism for multiple food sources might reflect a troglomorphic adaptation to an environment where seasonal water flows create sudden changes in nutrient provision.

\section{Conclusions}

To the best of our knowledge, this report is the first report to describe a behavioral experiment performed on 

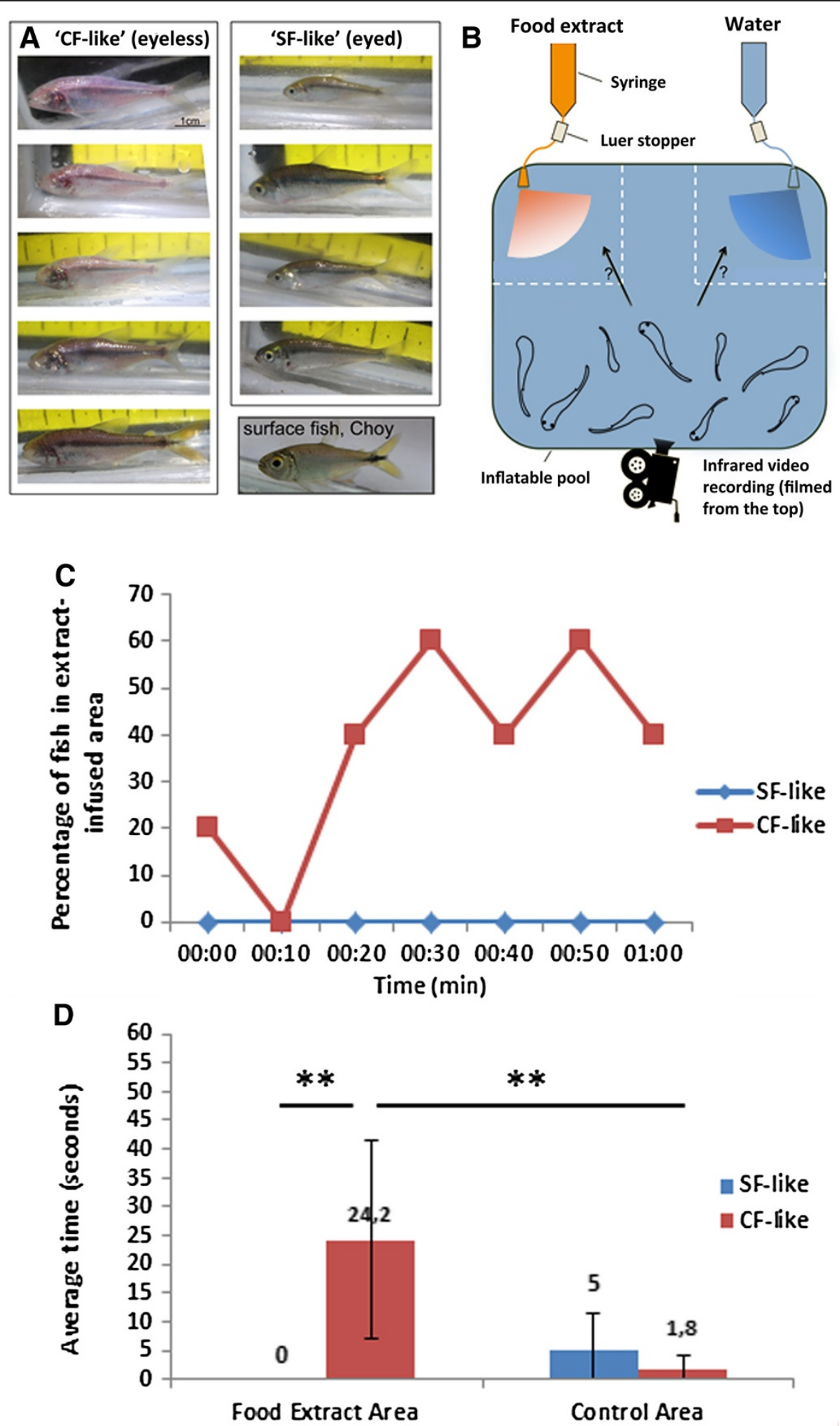

Figure 2 Behavioral responses to food extract in Subterráneo fish. (A) Both cavefish (CF)-like troglomorphic and surface fish (SF)-like nontroglomorphic fish were used for the behavioral test. On the bottom right, a SF from the Nacimiento del Río Choy is shown for comparison. (B) Schematic of experimental setup. See Methods for details. (C) Percentage of SF-like and CF-like fish that were in the food extract-infused quadrant of the pool after solution administration (10-s intervals). (D) Average time (in seconds) spent by SF-like and CF-like fish in either extract-infused or control area ${ }^{* *} P<0.01 ;$ CF-like $=5$, SF-like $\left.=4\right)$. Error bars represent standard deviations; indicated numbers correspond to average values. 


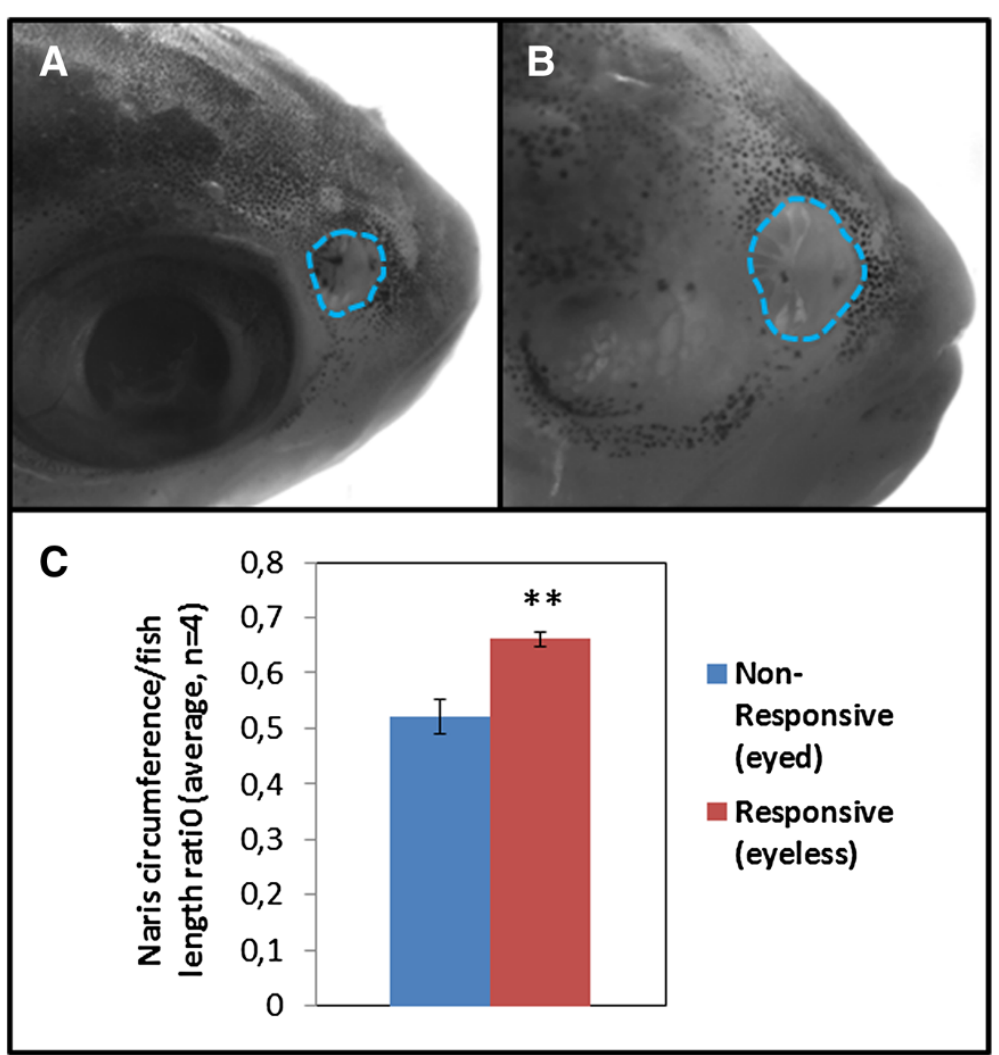

Figure 3 Naris size is correlated with eye loss and behavioral attraction to food extract. Measurements of naris circumference (dashed blue encircled areas) on individuals used for behavioral analysis revealed smaller naris size in surface fish-like fish (A) than in cavefish -like (B) after adjustment to fish body length (C) $(n=4, P<0.01)$.

wild Astyanax in their natural environment. The results obtained raise the intriguing possibility that olfactory capabilities might have evolved in cave-dwelling Astya$n a x$, and it is tempting to propose that this change improves food-finding in dark environments, where vision is useless. Additional studies are certainly necessary to better characterize the observed differences in chemosensory response and to test whether they correspond to bona fide sensory adaptations in Astyanax mexicanus (and potentially other cave-dwelling animals as well).

\section{Methods}

\section{Sampling and photography}

For assessment of the phenotypes encountered in the Subterráneo cave, fish were caught with a seine net and transferred to inflatable plastic pools. They were individually photographed with a Canon EOS 650D camera (Canon U.S.A., Melville, NY, USA) in a narrow glass box and returned to the pool. Fieldwork was performed under the auspices of Mexican permit 02241/13 (to SR) delivered by Secretaria de Medio Ambiente y Recursos Naturales.

\section{Behavioral test}

To collect fish for behavioral testing, a meat-baited minnow trap was set up overnight. The collected fish were placed in a $61-\mathrm{cm} \times 61-\mathrm{cm} \times 15-\mathrm{cm}$ inflatable pool and were left for an acclimatization period of $48 \mathrm{~h}$. Two 50-ml syringes were attached to a stationary tripod and connected to medical solution administration tubing containing a Luer stopper to control solution flow (Baxter, Thetford, UK). The ends of the two administration sets were attached to opposite corners of the plastic pool (Figure 2B). Food extract was prepared by adding $5 \mathrm{~g}$ of granular fish food (TetraDiskus; Tetra, Blacksburg, VA, USA) to $50 \mathrm{ml}$ of local water, mixing, and filtering using glass microfiber filters (Whatman plc, Kent, UK) to remove any food particles. This solution was added to one syringe while a water control was added to the other. Solution flow from the food extract and control samples was initiated simultaneously, and the experiment was filmed from the top using a Sony DCR-SR200 Handycam camcorder equipped with NIGHTSHOT mode (Sony Electronics, San Diego, CA, USA). Food extract and control areas were defined arbitrarily as $20-\mathrm{cm} \times 20-\mathrm{cm}$ zones adjacent to the two respective 
tube ends. To measure the time each fish spent in the food extract area, individual fish were manually tracked through frame-by-frame analysis of the movie using VirtualDub and ImageJ software (National Institutes of Health, Bethesda, MD, USA). A Mann-Whitney $U$ test was utilized to determine the statistical significance of the results. After the test, the fish were collected, photographed individually and returned to the pool.

\section{Naris size measurements}

Naris circumference and standard body length [18] were measured using ImageJ software and reported as a ratio to control for size variation between individuals.

\section{Additional file}

Additional file 1: Recording behavior in the Rio Subterráneo cave.

A one minute movie (infrared recording) shows attraction of "CF-like" but not "SF-like" fish to food-related odors. The "food" tubing is at the top left, and the "control water" tubing is at the top right of the plastic pool.

\section{Competing interests}

The authors declare that they have no competing interests.

\section{Authors' contributions}

$J B, A A, L E, M Y, M B, H H, L L, S P$ and $S R$ prepared for and performed field experimentation. AA performed the test and recorded the movie, alone, in the dark. JB and AA analyzed the data. JB, AA and SR wrote the paper. All authors read and approved the final manuscript.

\section{Acknowledgements}

We thank Ernesto Maldonado for help in obtaining the Mexican field work permit and Didier Casane, Julien Fumey and Karen Pottin for their help and enthusiasm during cave experimentation. This work was supported by ANR grants ASTYCO and BLINDTEST to SR. JB and AA receive ANR postdoctoral financial support.

\section{Author details}

${ }^{1}$ Equipe Développement Evolution du Cerveau Antérieur, UPR3294 N\&D, CNRS, Institut Alfred Fessard, Gif-sur-Yvette F-91198, France. ${ }^{2}$ School of Science, Marist College, Poughkeepsie, NY, USA. ${ }^{3}$ Department of Biology, University of Maryland, College Park, MD, USA.

Received: 1 July 2013 Accepted: 26 July 2013

Published: 4 September 2013

\section{References}

1. Protas M, Jeffery WR: Evolution and development in cave animals: from fish to crustaceans. Wiley Interdiscip/ Rev 2013, 1:823-845.

2. McCauley DW, Hixon E, Jeffery WR: Evolution of pigment cell regression in the cavefish Astyanax: a late step in melanogenesis. Evol Dev 2004, 6:209-218.

3. Sharma $S$, Coombs $S$, Patton $P$, Burt De Perera $T$ : The function of wallfollowing behaviors in the Mexican blind cavefish and a sighted relative, the Mexican tetra (Astyanax). J Comp Physiol Neuroethol Sens Neural Behav Physiol 2009, 195:225-240.

4. Yamamoto Y, Byerly MS, Jackman WR, Jeffery WR: Pleiotropic functions of embryonic sonic hedgehog expression link jaw and taste bud amplification with eye loss during cavefish evolution. Dev Biol 2009, 330:200-211.

5. Yoshizawa M, Goricki S, Soares D, Jeffery WR: Evolution of a behavioral shift mediated by superficial neuromasts helps cavefish find food in darkness. Curr Biol 2011, 20:1631-1636.
6. Gross JB: The complex origin of Astyanax cavefish. BMC Evol Biol 2012, 12:105.

7. Pottin K, Hinaux H, Rétaux S: Restoring eye size in Astyanax mexicanus blind cavefish embryos through modulation of the Shh and Fgf8 forebrain organising centres. Development 2011, 138:2467-2476.

8. Rétaux S, Pottin K, Alunni A: Shh and forebrain evolution in the blind cavefish Astyanax mexicanus. Biol Cell 2008, 100:139-147.

9. Yamamoto Y, Stock DW, Jeffery WR: Hedgehog signalling controls eye degeneration in blind cavefish. Nature 2004, 431:844-847.

10. Varatharasan N, Croll RP, Franz-Odendaal T: Taste bud development and patterning in sighted and blind morphs of Astyanax mexicanus. Dev Dyn 2009, 238:3056-3064.

11. Protas M, Tabansky I, Conrad M, Gross JB, Vidal O, Tabin CJ, Borowsky R: Multi-trait evolution in a cave fish, Astyanax mexicanus. Evol Dev 2008, 10:196-209.

12. Mitchell RW, Russell WH, Elliott WR: Mexican eyeless characin fishes, genus Astyanax: environment, distribution, and evolution. Spec Publ Mus Texas Tech Univ 1977, 12:1-89.

13. Wilkens H, Burns RJ: A new Anoptichthys cave population (Characidae, Pisces). Ann Spéléol 1972, 27:263-270.

14. Bradic M, Beerli P, García-De León FJ, Esquivel-Bobadilla S, Borowsky RL: Gene flow and population structure in the Mexican blind cavefish complex (Astyanax mexicanus). BMC Evol Biol 2012, 12:9.

15. Strecker U, Hausdorf B, Wilkens H: Parallel speciation in Astyanax cave fish (Teleostei) in northern Mexico. Mol Phylogenet Evol 2012, 62:62-70.

16. Schemmel C: Studies on the genetics of feeding behaviour in the cave fish Astyanax mexicanus f. Anoptichthys: an example of apparent monofactorial inheritance by polygenes. Z Tierpsychol 1980, 53:9-22.

17. Hüppop K: Food-finding ability in cave fish (Astyanax fasciatus). Int J Speleol 1987, 16:59-66.

18. Hinaux H, Pottin $K$, Chalhoub H, Père S, Elipot $Y$, Legendre L, Rétaux S: A developmental staging table for Astyanax mexicanus surface fish and Pachón cavefish. Zebrafish 2011, 8:155-165.

doi:10.1186/2041-9139-4-25

Cite this article as: Bibliowicz et al:: Differences in chemosensory response between eyed and eyeless Astyanax mexicanus of the Rio Subterráneo cave. EvoDevo 2013 4:25.

\section{Submit your next manuscript to BioMed Central and take full advantage of:}

- Convenient online submission

- Thorough peer review

- No space constraints or color figure charges

- Immediate publication on acceptance

- Inclusion in PubMed, CAS, Scopus and Google Scholar

- Research which is freely available for redistribution 